\title{
Analysis on the Basic Essentials of Marine Engineering Safety Management in China's Coastal Areas
}

\author{
Xue yingchun xueyingchun ( $\nabla$ xueyc@163.com ) \\ Wuhan University of Science and Technology \\ chenguoping chenguoping \\ Wuhan University of Science and Technology
}

\section{Research Article}

Keywords: Eastern China, Reverse management, Marine engine, Safety control, Engine management, Pacific safety

Posted Date: March 11th, 2021

DOI: https://doi.org/10.21203/rs.3.rs-239497/v1

License: (c) (i) This work is licensed under a Creative Commons Attribution 4.0 International License.

Read Full License 


\section{Abstract}

China's coastal areas have developed fisheries and busy maritime trade, which leads to the need for a large number of ships in eastern China. Ensuring the safe navigation of ships has become the focus of national management. The main purpose of this paper is to improve the level of marine engine safety management. The safety check list and reverse management model are used to check and measure the marine engine safety. The results show that the test results are $M 1=95.81$ and $M 2=96.35$ respectively, which indicates that the safety model of reverse management plays a positive role in the actual operation.

\section{Introduction}

In recent years, fishing vessel accidents occur frequently in China [1-3]. For example, there are nearly 20000 fishing boats in Liaoning Province, most of which are equipped with four-wheel hydraulic winch, which is favored by the majority of fishermen for its advantages of large pulling force and fast net pulling speed. However, there are also serious safety risks, such as finger breaking in light cases and arm breaking in heavy cases [4]. Most of the wooden fishing boats above 60hp in Hebei Province have purchased four wheel winders and eliminated the original two wheel ones. Through practical application, it has really played a role in increasing work efficiency and improving economic benefits. However, we can also see that the number of casualties of fishing boat crew has increased significantly. According to preliminary statistics, there were more than 120 net gear accidents in 2000 in the whole province, seriously injuring more than 30 crew members, which seriously affected the fishery safety situation [5]. These situations are closely related to ship automation.

Countries close to the sea attach great importance to fishery production and ship design and management. For example, China and Japan are both traditional aquatic powers [6]. In the vast ocean area, marine fishing fishery is an important part of marine fishery [7]. China's pelagic fishery started in 1985. After more than 30 years of development, it has made great achievements from scratch, from small to large, from weak to strong. The data shows that in 2014, China's offshore fishing output was 3.02 million tons, with a total output value of 18.5 billion yuan. There were more than 2460 pelagic fishing vessels operating, with a total power rate of nearly 1 million kilowatts. The overall fleet size and offshore fishery output rank first in the world [8].

After years of development, the automation level of fishing vessels has been continuously improved. Its development stage can be divided into five stages: single system automation, general ship automation, unmanned ship control, super automatic ships and future ships. One of the problems is the safety management of marine engine room [9]. The innovation of this paper is mainly to put forward the reverse model safety management design for the safety management of fishing vessels, so as to provide necessary guidance for ship manufacturing and operation management.

\section{Journals Reviewed}


In recent decades, China's competent authorities have always regarded the navigation safety and engine management of fishing vessels as key factors, which has been recognized by scholars. For example, Liu Yanjie and Lu Liang [11] put forward their own views on strengthening the safety management of fishing vessels. Cui Kai [12] and others have made relevant research on the safety management of ocean going fishing vessels from the perspective of ISM rules. Zhang Weidong [13] proposed to strengthen the inspection management of fishing vessels to ensure the safety of fishery production. Zhang Guanqun [14] and others carried out a reasonable division of the channel from the perspective of port management, so as to improve the safety management of fishing vessels. Liu Wei [15] believed that the potential safety hazards mainly come from meteorological disasters, ship quality and crew quality. In combination with business philosophy and production practice, we should strictly control the "three key points" to strengthen the safety work of fishing vessels. Xiao Yang [16] realized the auxiliary decision-making role of the information platform in fishery production and safety management through the fishing vessel data center, fishing vessel management information platform and Internet, thus forming the research on the construction of fishing vessel management information system, which has positive significance for the safety of fishing vessels. Xu Peiqing and Wang Zhiwei [17] control the risk of fishing vessels from the perspective of strengthening fire safety management of fishing vessels in autumn and winter.

Many experts put forward special methods for marine engine safety management. For example, Zheng Fuyong [18] described the marine power unit, analyzed the existing safety problems of marine engine in the new period, proposed measures to strengthen safety management, and finally put forward safety management measures for human factors engineering. Wang Lei [19] analyzed the risks caused by human, equipment and environment in marine engineering management, and how to assess and manage risks, and put forward relevant suggestions. Chen Liwei [20] proposed safety management measures for modern marine engine room, which is the core of ship operation and has strong complexity and comprehensiveness. Zhang Haibin [21] realized that the level of the engine manager not only affects the operation efficiency of the ship, but also affects the safety of the ship, so he put forward suggestions for comprehensive management. Gaiyong [22] has done relevant research on the relationship between maintenance engineering and safety risk management. Tien Anh tran [23] made relevant research on the relationship between high-efficiency application of energy and turbine management. A. Nour eddine [24] and others analyzed the benefits of marine engine management based on the optimization and characteristics of the prototype thermoelectric generator for marine engine, and put forward suggestions for the safety of marine engine management.

The above research analyzed the potential risks and solutions from various levels. This study proposed a different research method from the previous research methods, mainly from the perspective of engine management, detailed analysis of the main engine, electrical, auxiliary aircraft, high altitude and maintenance and other five subsystems to supervise and control the safety of fishing boat engine management. Through the systematic inspection of the two wheelset engine, the theory of safety management and control force field is put forward to provide some reference for the future marine engine safety management and fishery ship power manufacturing. 
2 Safety analysis and model design of marine engine management

2.1 Research methods of marine engineering safety management

According to the operation characteristics of marine engine, the safety management system of marine engine is divided into five variable indexes: main engine, electrical equipment, auxiliary engine, high altitude and maintenance. Then the weights of five variables were determined by 1-9 scale method. Secondly, the weighted average method is used to determine the overall data security level of the safety management system of offshore fishing vessels. Finally, the positive and negative management method is used to verify and improve the safety level repeatedly.

\subsection{Safety classification of Marine Engineering Management}

The safety level of marine engineering management system and index is divided and determined. First, it is necessary to determine the safety classification standard of marine engine safety management system and index. See Table 1 for the classification standard. Secondly, the expert scoring method is used to check the safety of each index of marine engine safety management. According to the results of the checklist, the corresponding safety evaluation standard is obtained, and then the safety level of the index is determined according to the safety classification standard. Therefore, the research team has prepared a risk assessment form for marine engine (see Table 1).

Table 1 Security Level Score Level

\begin{tabular}{|c|c|c|c|}
\hline Evaluation & Mark & Specific interpretation & $\begin{array}{l}\text { Safety } \\
\text { level }\end{array}$ \\
\hline $0 \leq \mathrm{M} \otimes 80$ & 0 & $\begin{array}{l}\text { Very low level, stop operation, need to take immediate safety } \\
\text { management measures }\end{array}$ & high-risk \\
\hline $80 \leq \mathrm{M} \otimes 85$ & 1 & $\begin{array}{l}\text { The level is very low, we must take measures to find the problem } \\
\text { point and judge the severity }\end{array}$ & $\begin{array}{l}\text { Moderate } \\
\text { risk }\end{array}$ \\
\hline $85 \leq \mathrm{M} \otimes 90$ & 2 & Measures should be taken if the level is low & $\begin{array}{l}\text { Critical } \\
\text { safety }\end{array}$ \\
\hline $90 \leq \mathrm{M} \otimes 95$ & 3 & $\begin{array}{l}\text { Medium, measures can be taken to further improve the level of } \\
\text { safety management }\end{array}$ & $\begin{array}{l}\text { General } \\
\text { safety }\end{array}$ \\
\hline $\begin{array}{l}95 \\
\leq \mathrm{M} \leq 100\end{array}$ & 4 & The existing safety management level should be maintained & $\begin{array}{l}\text { Strong } \\
\text { safety }\end{array}$ \\
\hline
\end{tabular}

According to the above indexes, the weight coefficient and quantity safety checklist of safety management indexes of ocean going fishing vessels are obtained, and the safety evaluation scores of each index are obtained, and the overall safety evaluation score of marine engine management is 
obtained by weighted average method. Assuming that the overall safety score of the marine engine safety management system is $m$, then

$$
\mathrm{M}=\sum_{i=0}^{n} R_{i} \cdot M_{i}
$$

$\mathrm{N}$ in the above formula (1) is the number of safety management indicators; $\mathrm{Rl}$ is the weight coefficient of safety management indicators, and R (ratio) meets the conditions:

$$
\sum_{\mathrm{i}=0}^{\mathrm{n}} R_{\mathrm{i}}=1
$$

According to table 1 , the overall safety level of the marine safety management system is $\mathrm{m}$. The strength, time and quantity of safety management measures are different in different levels. If the safety level of the marine engine safety management system obtained through the safety management evaluation is lower than 80 points, it indicates that the marine engine safety management is weak and the probability of accidents is very high. Therefore, it is necessary to stop production immediately for inspection and implement effective measures to continue operation. If it is in the first level, it is necessary to pay close attention to it and take decisive measures.

\subsection{Conceptual design of positive and negative management model}

The anti management model is mainly based on the standards and specifications related to the marine engineering management and operation system, which is used to discriminate and check the known hazard categories, design defects and potential hazards and harmfulness related to general process equipment, operation and management. In order to ensure that the inspection items are comprehensive, the inspection objects are divided into several evaluation indexes in advance, and the inspection items list is listed in the form of expert scoring, so as to find out the shortcomings and constantly stimulate and feedback, so as to improve the quality of internal management factors and finally reach the highest level of safety management.

Concept analysis of marine engineering safety counter management. The common management is called positive management, the purpose is to make the development of things not deviate from the goal and run correctly, while the anti management is to start from the loopholes and negligence of positive management to form the supplement to the positive management. Strictly speaking, anti management is a part of positive management, but positive management can not cover all aspects. The purpose and effect of positive management will be affected by too many problems or human slack. Therefore, this study puts forward the anti management thinking, which is aimed at the minor negligence and deficiency in the marine engineering management, and initiates the maintenance and correction. The purpose is to avoid the accidents in the operation of the marine engine, so as to remedy the deficiencies of the 
management. Therefore, the research team designed a specific model of security inspection(see Fig.1), In the second measurement, according to this model(Fig.1), we pay special attention to risk control.

The model $₫$ see Fig. $1 \rrbracket$ takes the marine engine power as the core, electrical as the support, auxiliary aircraft, high altitude and maintenance as the intervention, and takes the first level as the initial operation center. After a round of inspection, the safety scores of five subsystems in the engine management are obtained. Through feedback and stimulation to the second level of management, and then in the production process for two rounds of inspection and correction, until the highest level of safety. In this study, the safety evaluation model of marine engine management is established based on the risk mining. The model is used to evaluate the safety management of offshore ships of a fishery enterprise in Qidong City, Jiangsu Province, and it is proved that the model can improve the safety management level of marine engineering management.

\section{Method}

\subsection{Application of anti management model in Marine Engineering Management}

The safety evaluation model based on anti management is applied to the safety management evaluation of marine engine of a pelagic fishing vessel in Qidong City, Jiangsu Province. The steps are as follows: firstly, the marine engine management system is divided into five safety indexes, and the weight coefficient of each index is determined by accident statistics method. The second is to get the result score of each index's safety checklist through the anti management model, and get the safety evaluation score of each index. According to the safety management system and its index's safety classification table, the safety grade of the index is determined. Thirdly, according to the safety evaluation score and corresponding weight coefficient of subsystem indexes, the overall safety level of engine room is obtained by weighted average method.

\subsection{Weight coefficient determination}

According to the actual situation of marine engineering management, the appropriate weight determination method is selected. For the marine engineering management of offshore fishing vessels, the weight coefficient of each risk factor can be obtained according to the statistical results of accidents. In this study, we invited the ship safety management experts with more than 20 years of relevant experience to score and count the factors. Ten ocean fishing vessel safety management experts (3 experts from the Municipal Bureau of ocean and fisheries, 3 experts from Jiangsu Huanghai Fisheries Research Institute, and 4 masters of offshore fishing vessels affiliated to Qidong City) scored and counted the five factors of engine, electrical, auxiliary, high altitude and detection, and the total score was controlled within According to the results, the influence coefficient of the main engine can be set as 31.4; similarly, the safety index coefficient of electrical facilities is 21.9; the safety index coefficient of auxiliary engine is 18.2; the safety index coefficient of high-altitude operation is 11.3; and the safety index coefficient of engine detection is 17.2. Of course, other factors are also very important, such as the implementation of safety culture training and system construction to improve the level of safety 
management, marine management is no exception. This study focuses on the safety and operation of marine engineering management, without considering the influence of safety culture.

Due to the strong subjectivity of the above methods, according to references [25], [26], and [27], new weights are defined by 1-9 scale method, fuzzy matrix and triangular fuzzy number method. According to the calculation results and dimension reduction, the weight ratio is $(0.325,0.209,0.191,0.104,0.171)$.

\subsection{Determination of safety level of marine engineering safety management index}

With the development of science and technology, the modern marine engine is also developing towards intelligence and automation. However, under the system of technical control, there are also many disadvantages, and the frequency of marine engine accidents is obviously increased [28]. The safety of marine engine is an important part of ship manufacturing and long-distance navigation. As the core of ship operation, engine room has strong complexity and comprehensiveness, Therefore, special attention should be paid to the operation and safety management [29]. According to the relevant discussions of $\mathrm{Yu}$ Peiwen and Yuan Jianbin [30] on fishing vessel engine, the expert scoring was focused on five safety management elements. The results are as follows (table 2-table 6).

Table2 Safety inspection of main mechanical equipment 


\begin{tabular}{|c|c|c|c|c|}
\hline $\mathrm{N}$ & \multicolumn{2}{|l|}{ Detailed } & TS & Result \\
\hline 1 & \multicolumn{2}{|c|}{$\begin{array}{l}\text { The opening pressure of explosion-proof valve of scavenging box of diesel } \\
\text { engine shall not exceed } 1.1 \text { times of the maximum }\end{array}$} & 5 & 4.92 \\
\hline 2 & \multicolumn{2}{|c|}{$\begin{array}{l}\text { Hydraulic test of cooling water for cylinder head, cylinder and piston of diesel } \\
\text { engine, } 0.7 \mathrm{MPa}\end{array}$} & 5 & 4.95 \\
\hline 3 & \multicolumn{2}{|c|}{$\begin{array}{l}\text { The calibration opening pressure of cylinder safety valve is } 1.4 \text { times of the } \\
\text { maximum combustion pressure }\end{array}$} & 5 & 4.98 \\
\hline \multirow[t]{2}{*}{4} & \multirow[t]{2}{*}{$\begin{array}{l}\text { The dynamic balance test of the impeller of the } \\
\text { exhaust gas turbocharger shall be in } \\
\text { accordance with }\end{array}$} & $\begin{array}{l}\text { When } \mathrm{n} \leq 20000 \mathrm{R} / \mathrm{min} \\
\text { the impeller eccentricity e > } \\
0.02 \mathrm{~mm}\end{array}$ & 5 & 4.95 \\
\hline & & $\begin{array}{l}\text { When } \mathrm{n}>20000 \mathrm{R} / \mathrm{min} \text {, the } \\
\text { impeller eccentricity e } \leq \\
0.01 \mathrm{~mm}\end{array}$ & 5 & 4.96 \\
\hline 5 & \multicolumn{2}{|c|}{$\begin{array}{l}\text { The } 1.5 \mathrm{p} \text { and not less than } 0.4 \mathrm{MPa} \text { hydraulic test is carried out on the } \\
\text { turbocharger shell to check whether there are cracks }\end{array}$} & 5 & 4.78 \\
\hline 6 & \multicolumn{2}{|c|}{ The intercooler shall be subjected to $1.25 \mathrm{p}$ hydraulic test } & 5 & 4.87 \\
\hline 7 & \multicolumn{2}{|c|}{$\begin{array}{l}\text { Diesel engine seat tight fitting bolts shall not be less than } 15 \% \text { of the total } \\
\text { number and not less than } 4 \text { bolts }\end{array}$} & 5 & 4.99 \\
\hline 8 & \multicolumn{2}{|c|}{ The thickness of gasket is between $10-75 \mathrm{~mm}$, steel $\leq 25 \mathrm{~mm}$, cast iron $\leq 25 \mathrm{~mm}$} & 5 & 4.96 \\
\hline 9 & \multicolumn{2}{|c|}{$\begin{array}{l}\text { The load test after power repair shall reach the calibration value, which shall not } \\
\text { be less than } 75 \% \text { of the calibration value, and the time shall be } \geq 2 \mathrm{H}\end{array}$} & 5 & 4.95 \\
\hline 10 & \multicolumn{2}{|c|}{$\begin{array}{l}\text { After maintenance, the windlass, steering gear and lifting equipment shall have } \\
\text { no-load operation test for no less than } 30 \text { minutes }\end{array}$} & 5 & 4.56 \\
\hline 11 & \multicolumn{2}{|c|}{$\begin{array}{l}\text { Check the relief valve and safety valve on the steering gear hydraulic system, } \\
\text { and the opening pressure is less than } 1.1 \text { times of the maximum load }\end{array}$} & 5 & 4.76 \\
\hline 12 & \multicolumn{2}{|c|}{$\begin{array}{l}\text { The total displacement of the air compressor fills all the start-up air bottles of } \\
\text { the main engine within } 1 \text { hour }\end{array}$} & 5 & 4.89 \\
\hline 13 & \multicolumn{2}{|c|}{$\begin{array}{l}\text { The tightness of air bottle and piping system is less than or equal to } 4 \% \text { within } \\
24 \mathrm{~h} \text {, or there is no air leakage when immersed in water for } 3 \text { minutes }\end{array}$} & 5 & 4.98 \\
\hline 14 & \multicolumn{2}{|c|}{$\begin{array}{l}\text { The safety valve of air cylinder shall be calibrated, with opening pressure } \leq 1.1 \\
\text { times and closing pressure } \geq 85 \% \text { of working pressure }\end{array}$} & 5 & 4.97 \\
\hline 15 & \multicolumn{2}{|c|}{$\begin{array}{l}\text { The air bottle with fusible plug shall be set to check whether its technical } \\
\text { condition is normal in combination with internal inspection }\end{array}$} & 5 & 4.98 \\
\hline 16 & \multicolumn{2}{|c|}{$\begin{array}{l}\text { The power piping system is generally checked by hydraulic test at } 1.5 \text { times the } \\
\text { working pressure }\end{array}$} & 5 & 4.76 \\
\hline 17 & \multicolumn{2}{|c|}{$\begin{array}{l}\text { When the surface temperature of power pipe wall exceeds } 60^{\circ} \mathrm{C} \text {, the insulation } \\
\text { material or protective layer shall be wrapped }\end{array}$} & 5 & 4.51 \\
\hline
\end{tabular}

Results $=$ score $/$ total score $=87.72 / 90=87.72 \%$, the index value was 97.47 
TS:Total score

Table 3 Safety inspection of electrical equipment

\begin{tabular}{|c|c|c|c|c|}
\hline$N$ & \multicolumn{2}{|l|}{ Detailed } & TS & Result \\
\hline 1 & \multicolumn{2}{|c|}{$\begin{array}{l}\text { After maintenance of generator or converter, check whether it is normal to } \\
\text { operate with maximum load for } 1-2 \mathrm{~h}\end{array}$} & 5 & 4.93 \\
\hline 2 & \multicolumn{2}{|c|}{$\begin{array}{l}\text { The temperature rise test of generator shall not be less than } 4 \mathrm{~h} \text {, and the } \\
\text { temperature rise shall not exceed the limit value }\end{array}$} & 5 & 4.91 \\
\hline 3 & \multicolumn{2}{|c|}{$\begin{array}{l}\text { The load of generator parallel operation test shall be between } 20 \% \text { and } \\
\text { maximum load }\end{array}$} & 5 & 4.87 \\
\hline 4 & \multirow[t]{3}{*}{$\begin{array}{l}\text { The reliability of protection } \\
\text { device should be checked for } \\
\text { automatic switch }\end{array}$} & $\begin{array}{l}\text { When the overload is } 10 \%-20 \% \text {, the delay } \\
\text { switch with less than } 2 \text { minutes shall be } \\
\text { disconnected }\end{array}$ & 5 & 4.91 \\
\hline 5 & & $\begin{array}{l}\text { Situation of reverse power protection device } \\
\text { of generator in parallel operation }\end{array}$ & 5 & 4.91 \\
\hline 6 & & $\begin{array}{l}\text { Undervoltage protection state of generators } \\
\text { in parallel operation }\end{array}$ & 5 & 4.93 \\
\hline 7 & \multicolumn{2}{|c|}{$\begin{array}{l}\text { After maintenance, the motor should be loaded for more than } 1 \text { hour without } \\
\text { knocking, overheating and vibration }\end{array}$} & 5 & 4.96 \\
\hline 8 & \multicolumn{2}{|c|}{$\begin{array}{l}\text { The rewinding motor shall be tested for balance, overspeed, withstand voltage } \\
\text { and temperature rise }\end{array}$} & 5 & 4.82 \\
\hline 9 & \multicolumn{2}{|c|}{$\begin{array}{l}\text { The temperature rise test shall be conducted on the mechanical device of the } \\
\text { maintenance motor, and the test time shall not be less than } 2 \mathrm{H}\end{array}$} & 5 & 4.84 \\
\hline
\end{tabular}

Results $=$ score $/$ total score $=43.17 / 45=76.67 \%$, the index value was 95.93

Table 4 Safety inspection of propeller shaft and stern shaft 


\begin{tabular}{|c|c|c|c|c|}
\hline $\mathrm{N}$ & \multicolumn{2}{|l|}{ Detailed } & TS & Result \\
\hline 1 & \multicolumn{2}{|c|}{$\begin{array}{l}\text { Generally, the } 0.05 \mathrm{~mm} \text { feeler gauge cannot be inserted into the keyway and } \\
\text { assembly, and it is allowed to be within } 20 \% \text { of the perimeter of the keyway }\end{array}$} & 5 & 4.83 \\
\hline 2 & \multicolumn{2}{|c|}{$\begin{array}{l}\text { The wear of the shaft sleeve shall not exceed } 50 \% \text { of the original thickness, the } \\
\text { stuffing box shall be less than } 60 \% \text {, and the cylindricity shall not exceed the limit }\end{array}$} & 5 & 4.87 \\
\hline 3 & \multicolumn{2}{|c|}{$\begin{array}{l}\text { The new copper sleeve was tested by } 0.15 \mathrm{Mpa} \text { water pressure test, and no } \\
\text { leakage was found within } 5 \text { minutes }\end{array}$} & 5 & 4.75 \\
\hline 4 & \multirow[t]{2}{*}{$\begin{array}{l}\text { Check that the clearance of } \\
\text { stern bearing does not } \\
\text { exceed the limit value }\end{array}$} & $\begin{array}{l}\text { There is no clearance at the lower part of the } \\
\text { bearing, and the measuring position shall be } 100 \\
\text { mm away from the stern tube end }\end{array}$ & 5 & 4.86 \\
\hline 5 & & $\begin{array}{l}\text { The thickness of eccentric boring of iron pear } \\
\text { wood bearing shall be no less than } 80 \% \text { of the } \\
\text { thickness of center boring }\end{array}$ & 5 & 4.87 \\
\hline 7 & \multicolumn{2}{|c|}{$\begin{array}{l}\text { The test pressure is } 1.5 \text { times of the working pressure, and the oil pressure is } \\
\text { used to check the tightness of the stern shaft oil lubricated bearing }\end{array}$} & 5 & 4.84 \\
\hline
\end{tabular}

Results $=$ score $/$ total score $=29.02 / 30=96.73 \%$, the index value was 96.73

Table5 Safety inspection of aerial work in Engine Department

\begin{tabular}{|clcc|}
\hline N & Detailed & TS & Result \\
\hline 1 & $\begin{array}{l}\text { Check the condition of scaffold, base plate, safety belt, mobile ladder and } \\
\text { lanyard }\end{array}$ & 5 & 4.56 \\
\hline 2 & Anti slip soft soled shoes, fasten the safety belt and hang it in a fixed position & 5 & 4.36 \\
\hline 3 & All tools and objects for aerial work shall be put in tool bags or tied with ropes & 5 & 4.87 \\
\hline 4 & It is forbidden to stay under the high-altitude operation area & 5 & 4.78 \\
\hline 5 & $\begin{array}{l}\text { In case of strong wind and big waves, it is strictly forbidden to work at height } \\
\text { except for special needs }\end{array}$ & 5 & 4.98 \\
\hline
\end{tabular}

Results $=$ score $/$ total score $=23.55 / 25=94.2 \%$, take the index value 94.20

Table 6 Safety inspection for engine maintenance 


\begin{tabular}{|clcc|}
\hline $\mathrm{N}$ & Detailed & TS & Result \\
\hline 1 & $\begin{array}{l}\text { When overhauling the main engine, the warning sign of "no motor train" shall be } \\
\text { hung at the control position, which shall be hung and unloaded by the person in } \\
\text { charge }\end{array}$ & 5 & 4.31 \\
\hline 2 & $\begin{array}{l}\text { For maintenance of auxiliary engine and auxiliary equipment, relevant warning } \\
\text { signs shall be hung at the control position and power control box }\end{array}$ & 5 & 4.35 \\
\hline 3 & $\begin{array}{l}\text { When overhauling the generator and motor, hang the warning sign forbidding } \\
\text { closing or take out the fuse }\end{array}$ & 5 & 4.78 \\
\hline 4 & $\begin{array}{l}\text { When repairing the air cylinder pressure cabinet, the pressure should be released } \\
\text { first, and it is forbidden to carry out maintenance with pressure }\end{array}$ & 5 & 4.81 \\
\hline 5 & \begin{tabular}{l} 
Disassembly and assembly of hot parts, protection facilities and equipment \\
\hline 6
\end{tabular} & $\begin{array}{l}\text { When repairing electrical equipment, live line operation or insulation tools are } \\
\text { strictly prohibited, and single person operation is strictly prohibited }\end{array}$ & 5 \\
\hline 7 & $\begin{array}{l}\text { Except for professionals, any external personnel shall not dismantle and repair } \\
\text { electrical equipment by themselves, and excessive fuse is prohibited }\end{array}$ & 5 & 4.43 \\
\hline
\end{tabular}

Results $=$ score $/$ total score $=32.38 / 35=92.51 \%$, the index value was 92.51

According to the index analysis in table 2-6, it can be seen from table 2 that the index safety assessment of the main engine equipment is 97.47 . According to table 1 , the security level of this item is level 4 , and the host level is higher. The score of Table 3 is 95.93 . According to table 1, the safety level of this item is 4 , and the electrical safety level is higher. The score of Table 4 is 96.73 , which indicates that the safety ratio of auxiliary engine is high. The score of table 5 is 94.20 , which indicates that there are some hidden dangers in the safety of high-altitude operation. The score of table 6 is 92.51 , which is in the third level, which indicates that the safety of engine maintenance needs to be strengthened. The overall inspection is shown in Fig. 2

\section{One round determination of marine engineering management safety level}

According to the algorithms in (1) and (2), the evaluation score of marine engine safety management system is as follows:

\section{$M^{1}=97.47 \times 0.325+95.93 \times 0.209+96.73 \times 0.191+94.2 \times 0.104+92.51 \times 0.171=95.81$}

According to table 1 , the safety level of the marine engine safety management system is level 4 , which belongs to the highest safety level. The main deficiencies are in aerial work and engine maintenance.

\section{The second round of safety management inspection}


Based on the above results, the research team summarized the safety management of the ship. According to the reverse management model design, after three months of targeted rectification, the research team launched a second round of safety inspection. The score of this safety assessment is as follows:

\section{$M^{2}=97.79 \times 0.325+96.43 \times 0.209+97.18 \times 0.191+94.63 \times 0.104+93.67 \times 0.171=96.35$}

The score data shows that the data of the second round of detection is higher than that of the first round, especially in the high-altitude operation and maintenance subsystem. The second round of safety management measures of the research team is effective (see Figure 2), and the rectification suggestions have been well applied, and have a good experience of the management role of reverse management.

It can be seen from Figure 2 that the second round is relatively higher than the first round $(96.35>95.81)$. The main reason is that the marine engineering and setting is relatively scientific and the foundation is relatively solid, while the man-made factors of high-altitude operation and maintenance are more affected by the safety culture. For an organization, an enterprise or an independent marine engineering management system, the promotion of safety culture needs a long process, and the infiltration of a culture needs to accumulate over time. Figure 3 also shows that it is not significant to improve the safety level only from the perspective of marine engineering management.

\section{Discuss}

The safety intensity of the hardware facilities of marine engineering management is high, even so, attention should be paid to prevent failures. In the case of wear and aging of marine machinery equipment and parts, obvious mechanical failure often occurs. Faults can lead to accidents. Common faults such as wear overrun, bolt looseness, weld cracking, etc. make the working capacity lose; the engine power decreases or the transmission system loses balance; the consumption of fuel and lubricating oil increases significantly. When the hardware facilities exceed the specified indicators, the failure is easy to occur. Therefore, the marine engineering management personnel should have intuitive consciousness of mechanical equipment.

The implementation of safety awareness and safety culture should be strengthened for the high altitude and maintenance of marine engine management. There is an inseparable relationship between human quality and marine engineering management. For the high-altitude operation and maintenance of the turbine, attention should be paid to the safety of the machinery and its own safety. We should be good at finding problems from the appearance, such as the leakage, emission, dripping and leakage of oil, water and gas during the operation of the ship engine, and the problem of burning engine oil from the exhaust smoke of black smoke and blue smoke. In addition, pay attention to the abnormal sound, smell and consumption. In the final analysis, these are closely related to the construction of marine engine safety culture. 
From the perspective of anti management, we must pay attention to the weak links. Ships sailing in the ocean for a long time, far away from the mainland, should be fully prepared for safety. The weak link is often the cause of failure, which leads to danger. The anti focus approach makes management more problem-solving. Turbine problems and failures are often known or premonitory, but there are no management measures to follow up, which brings a lot of hidden dangers for faults and accidents. By using the method of anti management, the professional maintenance personnel can focus on the core and find out the problem thoroughly, so as to lay a foundation for the safety of the marine engine.

To improve the level of safety management from the perspective of people. Marine engine is the focus of safety management, which requires human operation. To further strengthen the training of talents, we should not only learn book knowledge, but also enhance the ability of marine practice. This also shows from one side that no matter how advanced the machine is, professional and technical personnel are always the foundation.

\section{Limitations And Future Prospects}

Because the sample size is not large enough, some judgments and analysis are not deep enough. In addition, the idea of anti management focuses on the problem and lacks comprehensive inspection. The study found that in fact, the continuous follow-up inspection and improvement of the marine engineering management can not quickly improve the safety management level. The future research can expand the scope of research, increase the sample size, increase the research of safety culture, especially strengthen the training of marine professional and technical personnel, strengthen the foreign exchange, learn from the surrounding countries, especially Japan, in order to find out the unsafe factors in the marine engineering management.

\section{Declarations}

Acknowledge

This achievement is funded by the graduate innovation and entrepreneurship fund of Wuhan University

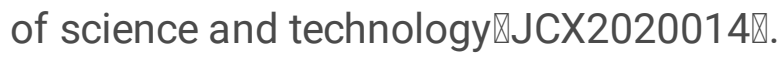

\section{References}

[1]Lu huadang. Frequent accidents of fishing vessels at sea [J]. Ocean and fisheries, 2011, 000 (012): 3031

[2] Shao jiangqun. Frequent maritime accidents and backward rescue system [J]. Zhejiang National People's Congress, 2008 (06): 45-45

[3] Wang yuanjiao. Status quo and Countermeasures of safety production of Zhejiang marine fishing vessels [D]. Zhejiang Ocean University, 2015

[4] Shi Dage, Liang Weibo, Guo Wenting. Measures to improve the safety of hydraulic drift net puller [J]. 
Fisheries modernization, 2004, 000 (003): 32

[5] Hu Qiang. Thinking about the four wheel winch accident of wooden fishing vessels in Hebei Province [J]. Fisheries administration, 2002

[6] Qi Bin. A brief introduction to the law enforcement system and equipment of the US, Japan and South Korea maritime police and thinking about China [J]. Ships and supporting facilities, 2015 (9): 22-31 [7] Yue Dongdong, Wu Fuxiu, Zhang Shuang, et al. Problems and Countermeasures of China's marine fishery output value accounting [J]. Fisheries information and strategy, 2020 (1): 1-6 [8] Shao Guilan, Chu Rui, Li Chen. Study on carbon balance of Marine Fisheries based on carbon emission and carbon sink Accounting: a case study of Shandong Province [J]. China fisheries economy, 2018 (4): 4-13

[9] Diao Yunfei. Modern marine engine safety management [J]. Construction engineering technology and design, 2018, 000 (022): 2471

[10] Huang Jiarong, LV huadang. It is a long way to go to develop offshore fisheries - an interview with Deng Jiazhuo, executive director of Guangdong Guangyuan Fishery Group Co., Ltd. [J]. Ocean and fisheries, 2016 (10): 36-37

[11] Liu Yanjie, Lv Liang. Problems and solutions in fishing vessel safety management [J]. China high tech enterprises (zhongxunzao), 2016, 000 (003): 193-194

[12] Cui Kai; Ren Yuqing; Sun Peng; Chen Lixin; research on safety management of offshore fishing vessels based on ISM rules [C] / / 60th anniversary of Chinese fishing vessel inspection.

[13] Zhang Weidong. Strengthening the inspection and management of fishing vessels to ensure the safety of fishery production [J]. China management informatization, 2019, 022 (015): 185-186

[14] Zhang Guanqun, Kong Xianwei, Li Yanwei, et al. Research on navigation risk and safety management of Tianjin central fishing port [J]. Tianjin navigation, 2018, 000 (003): 54-55

[15] Liu Wei. Strict control of "three passes" in fishing vessel safety work [J]. New agriculture, 2019 (18)

[16] Xiao Yang. Research on the construction of fishing vessel management information system in Liaoning Province [D]. 2016. Dalian Maritime University.

[17] Xu Peiqing, Wang Zhiwei. Strengthening fire safety management of fishing vessels in autumn and winter in Kenli District [J]. Qilu fisheries, 2018 (12): 59-60

[18] Zheng Fuyong. Marine engineering safety management in the new era [J]. Pearl River water transport, 2019 (17)

[19] Wang Lei, Yang Liu. Risk Study on marine engine safety management in the new era [J]. Modern salt chemical industry, 2019 (4)

[20] Chen Liwei. Research on safety management of modern marine engine room [J]. Ship materials and market, 2019

[21] Zhang Haibin. Research on safety management of modern marine engineering [J]. Pearl River water transport, 2019, 000 (008): 92-93

[22] Gai Yong. Research on safety risk management of overhaul project of Beihai rescue 115 [D]. 2016. Dalian Maritime University.

[23] Tien Anh Tran, Effect of ship loading on marine diesel engine fuel consumption for bulk carriers based on the fuzzy clustering method, Ocean Engineering, 2020ه207ه 
https://doi.org/10.1016/j.oceaneng.2020.107383

[24] Nour Eddine, D. Chalet, X. Faure, L. Aixala, P. Chess,Optimization and characterization of a thermoelectric generator prototype for marine engine application,Energy, 2018ه1438ख682-695. https://doi.org/10.1016/j.energy.2017.11.018.

[25] Zhou Zhen, sun Zhongyuan, Liu Fang, etc. Research on risk level classification model of production enterprises based on AHP [J]. Journal of Harbin University of technology, 2010 (1): 103-107

[26] Qian Yu. Fuzzy comprehensive evaluation of safety status of chemical enterprises based on AHP [J]. Chemical engineer, 2013 (2): 36-39

[27] Sun Xudong, Zhang Laixin, Qi Hongliang. Risk assessment model of coal mine safety production based on Fuzzy AHP [J]. Industry and safety and environmental protection 2014 (40) 1:65-68

[28] Gu Ming, Wang Fei, Wang Zihua. Analysis of modern marine engine safety management [J]. China Science and technology investment, 2017, 000 (006): 231

[29] Chen Liwei. Research on safety management of modern marine engine room [J]. Ship materials and market, 2019.

[30] Yu Peiwen, Yuan Jianbin. Management of fishing vessel engine (chief engineer, engineer) [M]. Dalian Maritime University Press. 2017: 50-68

\section{Figures}




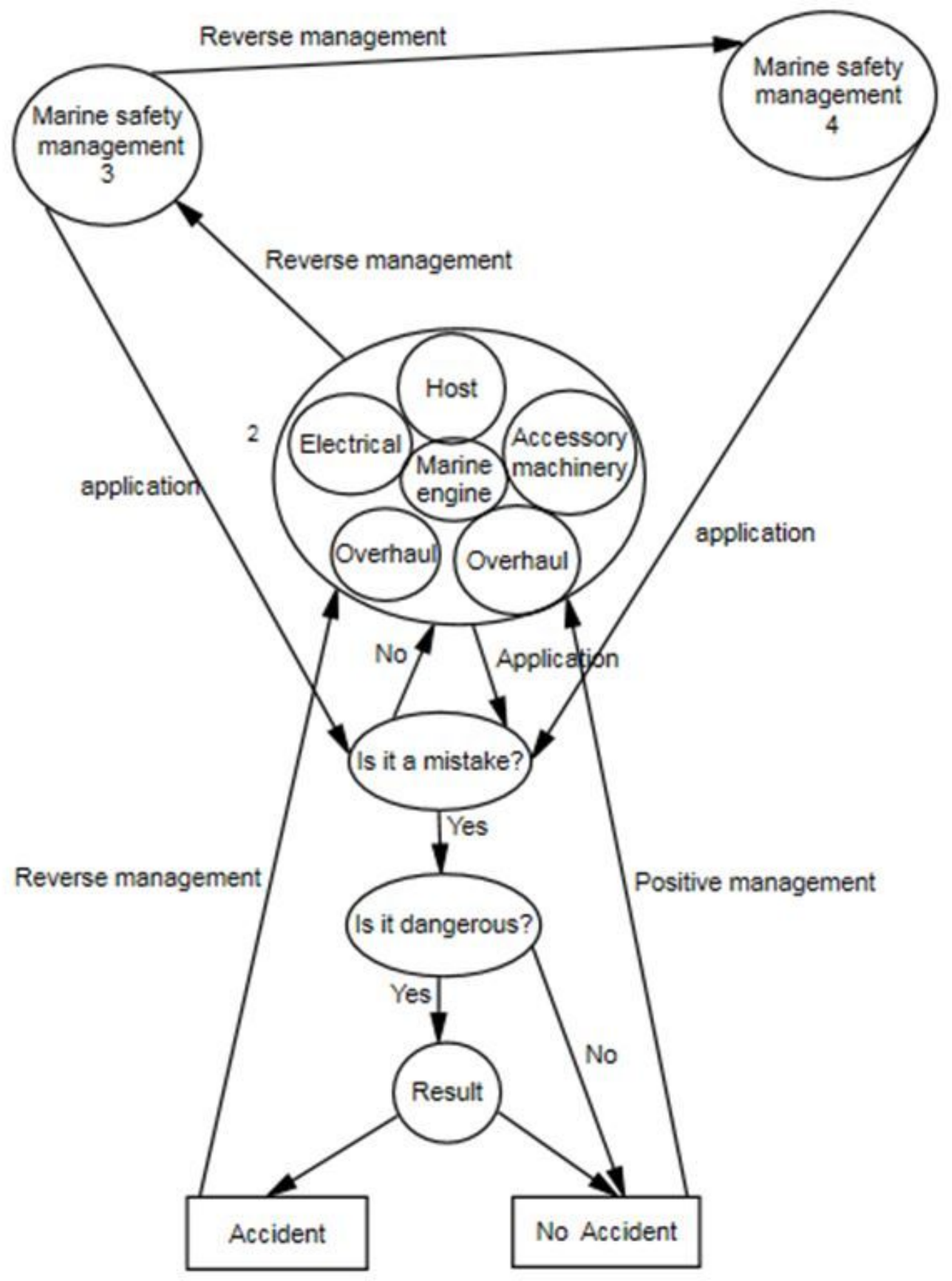

Figure 1

Reverse management model of marine engineering safety 


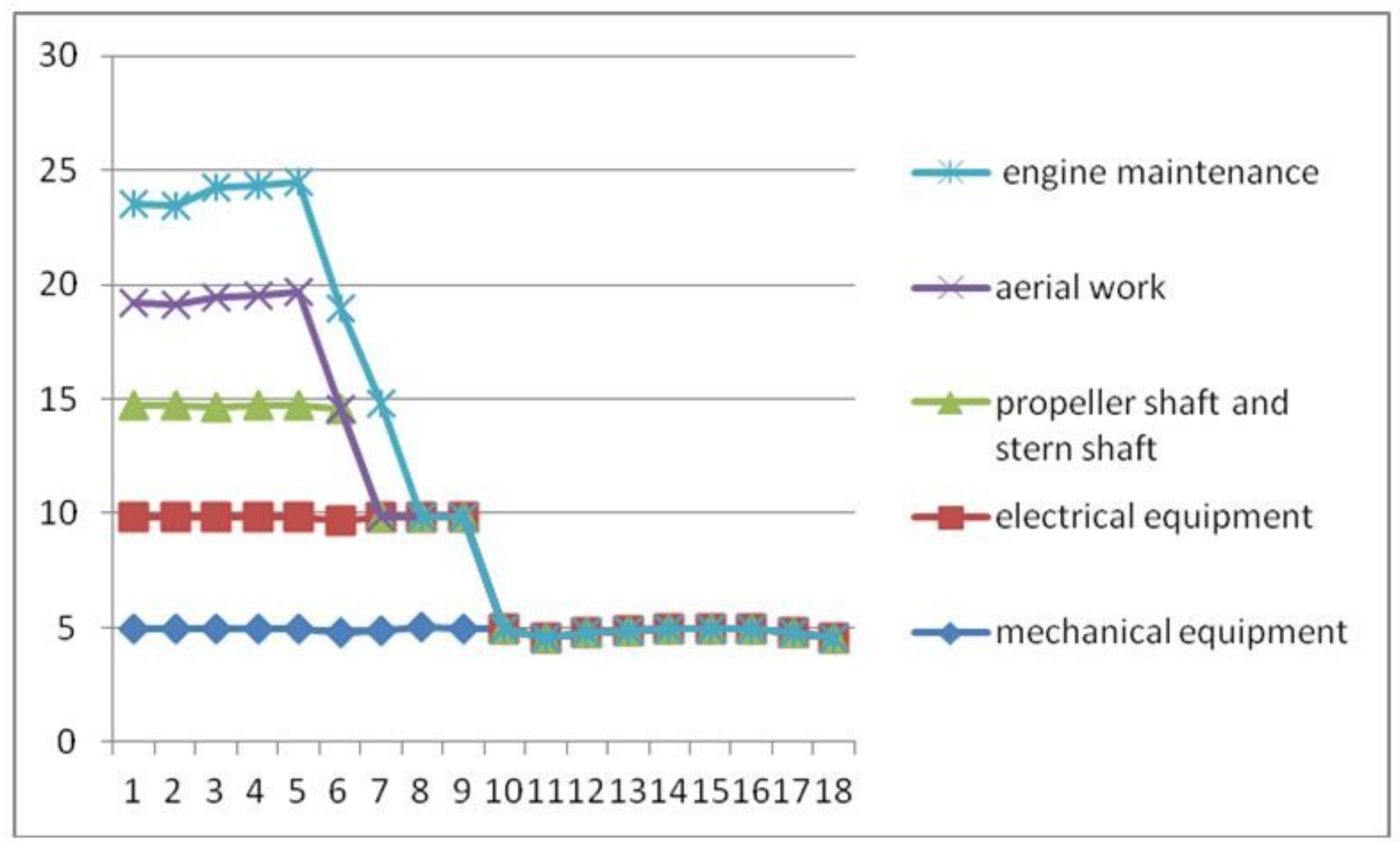

Figure 2

Overall inspection diagram

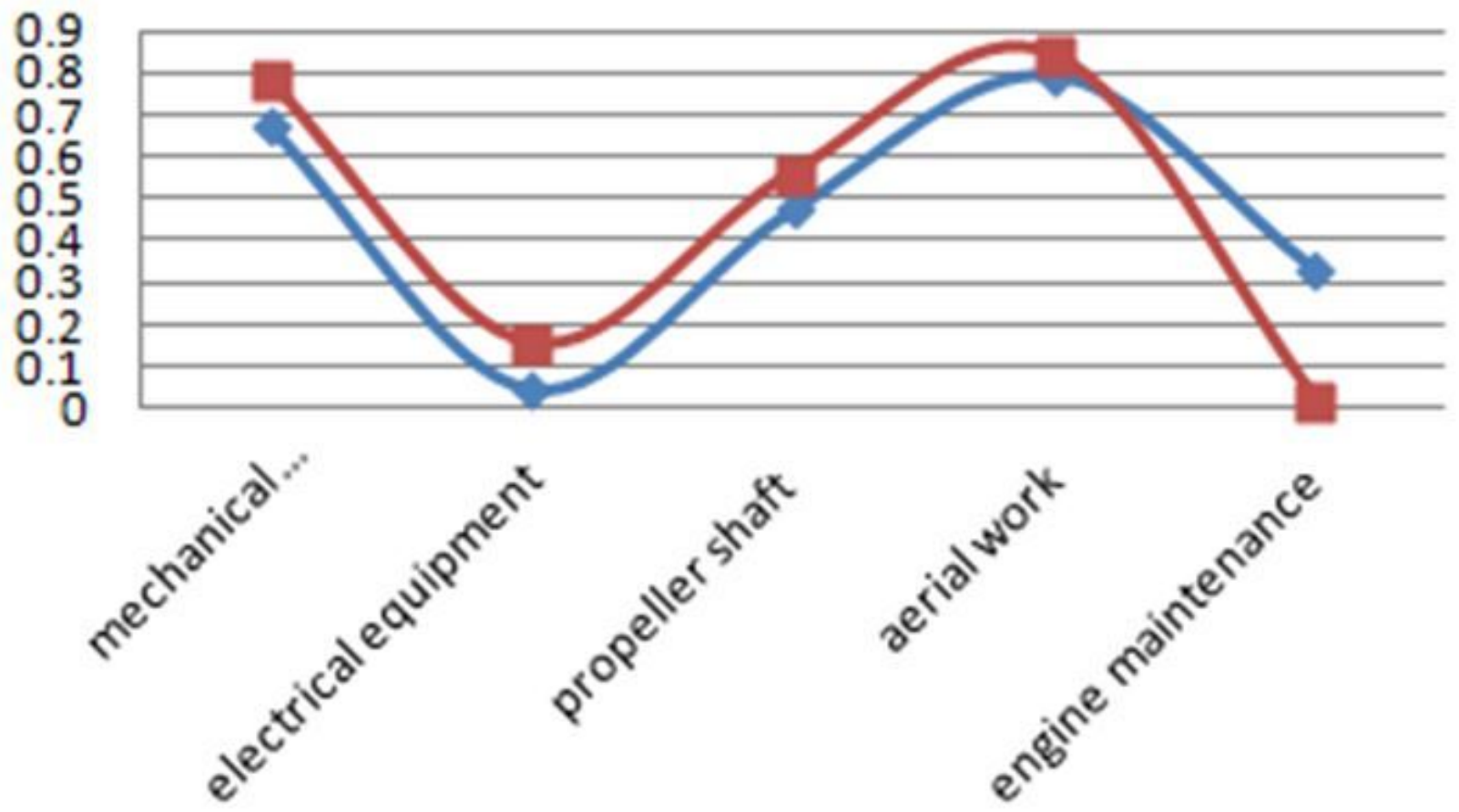

Figure 3 
Comparison of safety data

\section{Supplementary Files}

This is a list of supplementary files associated with this preprint. Click to download.

- Supplementarymaterial.docx 